Article

\title{
On the Effect of Thin Film Growth Mechanisms on the Specular Reflectance of Aluminium Thin Films Deposited via Filtered Cathodic Vacuum Arc
}

\author{
Gonzalo Rincón-Llorente ${ }^{1}$, Irene Heras ${ }^{2}{ }^{\mathbb{D}}$, Elena Guillén Rodríguez ${ }^{3}$, Erik Schumann ${ }^{4}$, \\ Matthias Krause ${ }^{4}$ and Ramón Escobar-Galindo ${ }^{5, *(D)}$ \\ 1 Physics of Surfaces and Materials, IK4-TEKNIKER, 20600 Eibar, Spain; gonzalo.rincon@tekniker.es \\ 2 Department of Applied Physics, University of Salamanca, 37008 Salamanca, Spain; iheras@usal.es \\ 3 Functional Surfaces and Nanostructures, Profactor GmbH, Im Stadtgut A2, 4407 Steyr-Gleink, Austria; \\ elena.guillen@profactor.at \\ 4 Helmholtz-Zentrum Dresden-Rossendorf, 01328 Dresden, Germany; e.schumann@hzdr.de (E.S.); \\ matthias.krause@hzdr.de (M.K.) \\ 5 Department of Materials Science, Metallurgical Engineering and Inorganic Chemistry, IMEYMAT, \\ University of Cadiz, 11510 Puerto Real, Spain \\ * Correspondence: ramon.escobar@uca.es; Tel.: +34-619-163-186
}

Received: 31 July 2018; Accepted: 12 September 2018; Published: 13 September 2018

\begin{abstract}
The optimisation of the specular reflectance of solar collectors is a key parameter to increase the global yield of concentrated solar power (CSP) plants. In this work, the influence of filtered cathodic vacuum arc deposition parameters, particularly working pressure and deposition time, on the specular and diffuse reflectance of aluminium thin films, was studied. Changes in specular reflectance, measured by ultraviolet-visible and near-infrared spectroscopy (UV-vis-NIR) spectrophotometry, were directly correlated with thin film elemental concentration depth profiles, obtained by Rutherford backscattering spectrometry (RBS), and surface and cross-sectional morphologies as measured by scanning electron microscopy (SEM) and profilometry. Finally, atomic force microscopy (AFM) provided information on the roughness and growth mechanism of the films. The two contributions to the total reflectance of the films, namely diffuse and specular reflectance, were found to be deeply influenced by deposition conditions. It was proven that working pressure and deposition time directly determine the predominant factor. Specular reflectance varied from 12 to $99.8 \%$ of the total reflectance for films grown at the same working pressure of $0.1 \mathrm{~Pa}$ and with different deposition times. This transformation could not be attributed to an oxidation of the films as stated by RBS, but was correlated with a progressive modification of the roughness, surface, and bulk morphology of the samples over the deposition time. Hence, the evolution in the final optical properties of the films is driven by different growth mechanisms and the resulting microstructures. In addition to the originally addressed CSP applications the potential of the developed aluminium films for other application rather than CSP, such as, for example, reference material for spectroscopic diffuse reflectance measurements, is also discussed.
\end{abstract}

Keywords: filtered cathodic vacuum arc; total and specular reflectance; thin film deposition conditions; structural characterisation

\section{Introduction}

The increasing degree of global industrialisation and high demand for fossil fuel is becoming a serious issue in gas emissions contributing to greenhouse effect terms. High efficiency renewable energy sources are a need in an ever-more energy demanding world. Concentrated solar power plants 
have proven to be a real clean alternative for energy harvesting. Nowadays, the largest concentrated solar power (CSP) plant, Ivanpah in USA, has an installed power of 390 MW [1]. A total production of $5 \mathrm{GW}$ was reached worldwide in 2017 by means of CSP plants which, translated into energy, represents $0.2 \%$ of the total energetic demand of electric energy [2]. Despite these numbers, efficiencies and costs of solar plants, or so-called levelized costs of energy, are still a "needs to improve" factor. Its technology is relatively novel compared with well-established competitors and consequently, there is still a large gap for improvement.

There are different types of CSP plants depending on the configuration of collectors and receivers. Parabolic dish, parabolic trough collectors, linear Fresnel collectors, and central tower systems [3] are the most commonly used ones and all of them have mainly the same operation schemes. Mirrors (solar collectors) concentrate solar radiation towards solar receivers, thereby increasing the temperature of a heat transfer fluid. Thermal energy is moved downstream by the heat transfer fluid and is converted into electricity by a heat exchanger and a steam turbine in a power generator.

Surface science and engineering solutions (in particular, thin film and plasma technologies) have been found to provide improvements to CSP plants by tackling at least three different key components: high reflecting thin film solar collectors, solar selective coatings [4] in the receivers, and anti-corrosion layers for protecting thermal storage tanks [5] (see Figure 1).

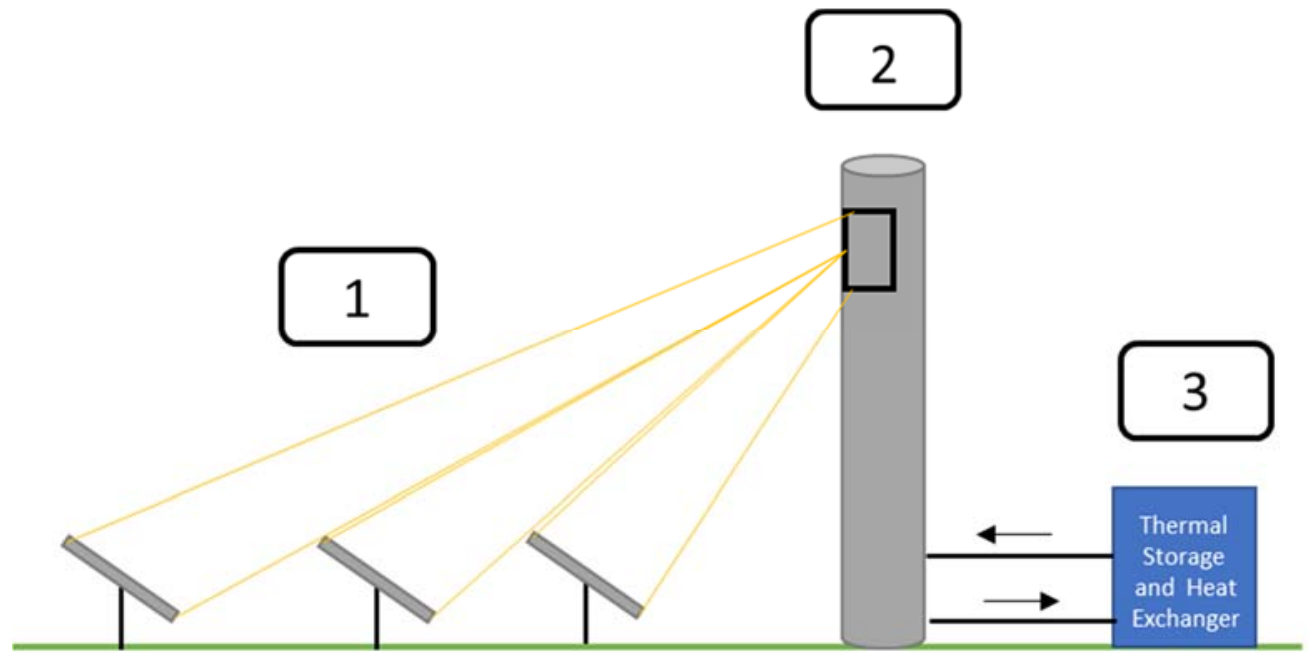

Figure 1. Schematic representation of the main components of a concentrated solar power plant, central tower system in this case. (1) Solar collectors (mirrors or heliostats), (2) solar receiver, and (3) thermal storage tanks.

Most of the CSP plants utilise second face mirrors fabricated by means of wet chemistry processes [6]. The reflectivity (solar weighted reflectivity) of commercial CSP ranges from 84 to 95\%. The highest reflectivity is achieved using silver as reflecting element [7]. Other commercial solutions with lower reflectance $(<90 \%)$ include aluminium and silvered polymer layers as reflecting materials [8]. However, main suppliers worldwide are investing in the development of dry fabrication processes such as physical vapour deposition (PVD) based technologies. PVD could bring improvements in optical properties and stability towards atmospheric inclemency. The increase in mirror specular reflectance (even at a few percentage points level) could significantly reduce the number of heliostats needed to reach the same temperatures at the solar receiver, bringing down the plant construction and operating expenses [9]. In this regard, the implementation of high energy PVD techniques such as filtered cathodic vacuum arc (FCVA) could yield high density reflecting thin films with improved reflectance and better environmental stability. The high density of the films achieved using FCVA, because of the high energy at which particles reach the substrate, was the main reason for choosing this technique among others. This density can improve corrosion resistance by reducing grain boundaries and surface roughness. 
In addition, improvements could also be achieved by modifying the manufacturing process. Nowadays, reflecting metals are chemically deposited in the back of extra clear glass in such a way that reflecting metals are atmosphere protected (second face mirror configuration), but partially scarifying the specular reflectance [10]. In first face mirrors, the reflecting material is deposited directly on top of the glass. However, the metal surfaces studied degraded rapidly due to weathering (i.e., rain or sand storms) and cleaning processes, causing a substantial decrease in the reflectance, thus making them unsuitable for solar thermal first face applications [11,12]. The development of atmosphere stable highly reflective coatings would open the possibility of the usage of cheaper substrates such as standard glass. This would dramatically decrease the solar plant costs as the extra clear glass holds approximately $60 \%$ of the final price of the CSP mirror $[13,14]$.

This study is aimed to achieve higher specular reflecting mirror surfaces to improve the yield of CSP solar plants. The studied first surface mirror concept is investigated as an alternative to well-established second surface mirror approaches, currently focusing on the reduction of the extra clear glass thickness on top of silver. Thereby, absorption-induced losses by the protective glass are prevented. In general, aluminium is a material presenting less durability issues than silver that is mainly used in state-of-the-art second surface mirrors. It is less prone to tarnishing than silver and it has a better mechanical performance. Moreover, aluminium forms an environmentally stable and hard natural oxide that could prevent or at least slow down mirror degradation. Finally, the $\mathrm{Al} / \mathrm{AlO}_{x}$ mirror concept has no internal interfaces that could undergo material failure. For that purpose, a series of aluminium thin films was deposited using FCVA at different working pressures and deposition times. The achieved optical performance of the films was studied depending on their structural properties. Rutherford backscattering spectrometry (RBS) was applied to explore the potential oxidation of the films during deposition or post-deposition air exposure. Surface morphological changes were explored by scanning electron microscopy (SEM). In addition, atomic force microscopy (AFM) measurements at different deposition times allowed exploring the dynamics of the growth mechanism of the films.

\section{Materials and Methods}

A set of aluminium thin films was deposited on glass slides and silicon (100) wafers using a $90^{\circ}$ pulsed FCVA equipment (Plasma Technologies, Kowloon, Hong Kong) [15]. Substrates were previously ultrasonicated for $10 \mathrm{~min}$ in (a) $0.5 \%$ Hellmanex solution in water, (b) acetone, and (c) ethanol. Before metal deposition, substrates were precleaned in the vacuum chamber with a flow of argon $(60 \mathrm{sccm})$ applying a DC bias of $750 \mathrm{~V}\left(80 \%\right.$ duty cycle) at $1.5 \mathrm{~Pa}$ for $15 \mathrm{~min}$. Truncated cones $\left(\Phi_{1}=65 \mathrm{~mm}\right.$, $\Phi_{2}=50 \mathrm{~mm}$, and height $=35 \mathrm{~mm}$ ) made of aluminium (99.99\%) were used as metallic targets for the depositions. The process was carried out applying a DC current of $20 \mathrm{~A}$ at an argon flow of $20 \mathrm{sccm}$ without bias current. The processes were performed at different pressures $(0.1,0.25,0.5$, and $1 \mathrm{~Pa})$ by controlling a throttle valve and at different deposition times $(2,5,10$, and $20 \mathrm{~min})$. An additional sample deposited at $0.1 \mathrm{~Pa}$ for one min was prepared in order to study by AFM the early stages of film growth. A summary of deposition parameters is shown in Table 1.

Table 1. Deposition parameters.

\begin{tabular}{cc}
\hline Parameter & Value \\
\hline Base Pressure (Pa) & $2 \times 10^{-4}$ \\
Working Pressure (Pa) & $0.1,0.25,0.5$, and 1 \\
Deposition Temperature & No intentional heating \\
Discharge current (A) & 20 \\
Bias & No bias applied \\
Deposition Time (min) & $1,2,5,10$, and 20 \\
\hline
\end{tabular}

Film thickness and roughness were measured using a mechanical profilometer DektakXT (Bruker, Billerica, MA, USA) from Bruker. It was equipped with a $4 \mu \mathrm{m}$ diameter diamond tipped stylus 
that applied $3 \mathrm{mg}$ force for these measurements. Root mean square roughness $(R a)$ was calculated according to the standard ISO4287-1997 [16].

Reflectance was measured using a Lambda 1050 spectrophotometer (Perkin Elmer, Waltham, MA, USA). The system was equipped with a deuterium and a tungsten halogen lamps covering the wavelength ranges of $175-320 \mathrm{~nm}$ and $320-3300 \mathrm{~nm}$, respectively. An integrating sphere (150 mm diameter) coated with Spectralon and the universal reflectance accessory (URA) were used to measure total and absolute specular reflectance, respectively. The integrating sphere has a photomultiplier tube (PMT) and InGaAs detectors and the URA accessory uses silicon and PbS detectors for the ultraviolet-visible (UV-vis) and near-infrared (NIR) region of the spectra, respectively. A calibrated silver mirror was used as reflectance reference.

For solar weighted reflectance (SWR) calculations, total and specular spectral reflectance $R_{\mathrm{T}, \mathrm{S}}(\lambda)$ were measured in a spectral range between $300 \mathrm{~nm}$ and $2500 \mathrm{~nm}$. SWR was obtained by calculating a weighted average using a referenced solar spectral irradiance $(G(\lambda)$, ASTM G173-03 AM 1.5), as defined in ISO 9050 [17]:

$$
S W R_{\mathrm{T}, \mathrm{S}}=\frac{\int_{\lambda_{1}}^{\lambda_{2}} R_{\mathrm{T}, \mathrm{S}}(\lambda) G(\lambda) d \lambda}{\int_{\lambda_{1}}^{\lambda_{2}} G(\lambda) d \lambda}
$$

Scanning electron microscopy (SEM) was performed for microstructure characterisation of the samples using a S5200 SEM (Hitachi, Tokyo, Japan) equipped with a field emission gun (FEG). Aluminium conducting samples were measured from top and cross-sectional views at $1-5 \mathrm{kV}$ electron beam energy.

Rutherford backscattering spectrometry (RBS) was measured on samples deposited on silicon substrate in Helmholtz-Zentrum Dresden-Rossendorf (HZDR) in Dresden, Germany using a $2 \mathrm{MeV}$ Van der Graaff accelerator by using ${ }^{4} \mathrm{He}^{+}$ions with an energy of $1.7 \mathrm{MeV}$. The data were acquired using a silicon barrier detector located at a backscattering angle of $170^{\circ}$, whose energy resolution was $13 \mathrm{keV}$. SIMNRA software was used for simulation of the layer's areal density and atomic composition [18].

Atomic force microscopy (AFM) images were measured using a NTEGRA Spectra II (NTMDT Spectrum instruments, Moscow, Russia) using a non-contact mode. Sample areas of $10 \mu \mathrm{m} \times 10 \mu \mathrm{m}$ were measured using NSG01 tips from NTMDT.

\section{Results and Discussion}

The series of aluminium thin layers deposited using FCVA at different working pressures $\left(P_{w}\right)(0.1$, $0.25,0.5$, and $1 \mathrm{~Pa})$ and during different deposition times (2, 5, 10, $20 \mathrm{~min})$ shows distinct differences in their visual appearance and reflectivity (Figure 2). At first glance, a low working pressure and short deposition times lead to highly reflective, higher working pressures and long deposition times to transparent films, respectively.

Table 2 shows the deposition rates of the films as a function of the working pressure calculated from the slope of the plot of the film thickness measured from profilometry versus the deposition time. A drastic decrease of the deposition rate with the working pressure is observed, and it varies from $27 \mathrm{~nm} / \mathrm{min}$ for samples deposited at 0.1 Pa down to less than $2 \mathrm{~nm} / \mathrm{min}$ for those prepared at $1 \mathrm{~Pa}$. It is known that in PVD processes, the working pressure affects the mean free path of particles in the plasma $[19,20]$. In short, at high working pressures, the collision probability of the impinging particles is high and subsequently, fewer particles with lower energies are able to reach the substrate surface, which results in lower deposition rates. Contrarily, at low pressures, the mean free path of the particles increases and a high density of energetic particles reach the substrate surface. Hence, all samples deposited at the highest working pressure are transparent or semi-transparent due to their low thickness ( $<10 \mathrm{~nm}$ for the longest deposition time of $20 \mathrm{~min}$ ). Samples prepared under intermediate working pressures $(0.5$ and $0.25 \mathrm{~Pa}$ ) showed an evolution from semi-transparent to opaque appearance and only those samples deposited at the lowest pressure of $0.1 \mathrm{~Pa}$ were found to be non-transparent within the complete time range under study. As stated in the introduction, the main objective of the 
work was the optimization of aluminium thin films for reflecting surfaces. Therefore, the detailed morphological, compositional, and optical study described below is focused on the series of samples deposited at $0.1 \mathrm{~Pa}$ as a function of the deposition time, which exhibits the best reflective properties according to the visual inspection.

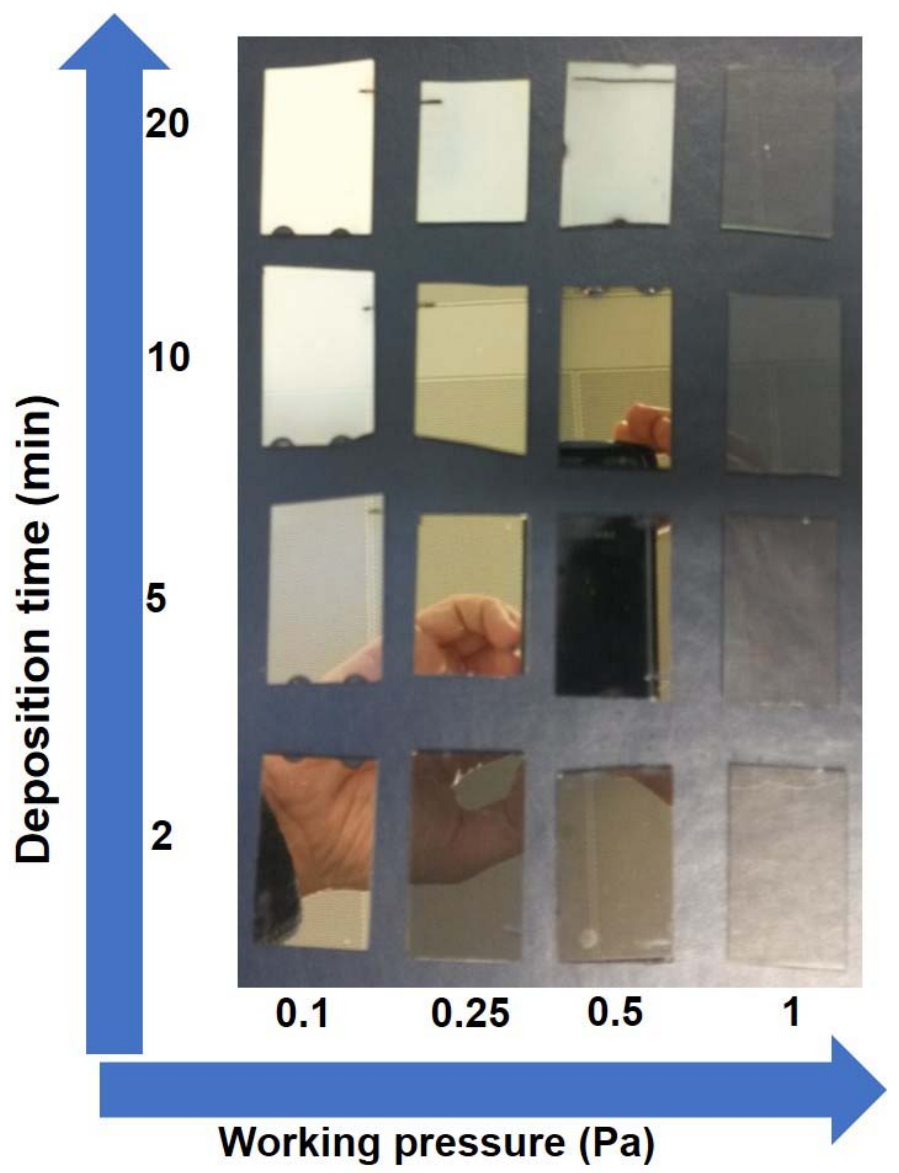

Figure 2. Photographs of aluminium thin films deposited at 0.1, 0.25, 0.5, and 1 Pa pressures and at 2, 5,10 , and 20 min deposition times on glass substrate.

Table 2. Dependence of the Al thin film deposition rates on glass substrates from the working pressures.

\begin{tabular}{cc}
\hline Working Pressure (Pa) & Deposition Rate (nm/min) \\
\hline 1 & $2 \leq$ \\
0.5 & $4.4 \pm 0.3$ \\
0.25 & $8.3 \pm 0.8$ \\
0.1 & $27 \pm 1$ \\
\hline
\end{tabular}

Samples ranging in thickness from 23 to $548 \mathrm{~nm}$, as measured by profilometry, were obtained (see Table 3). The elemental concentration depth profile of the set of samples prepared at $P_{w}=0.1 \mathrm{~Pa}$ $(t=2-20 \mathrm{~min})$ was obtained by RBS measurements. Figure 3 shows the RBS spectra of the samples together with their corresponding fit as obtained by SIMNRA. The deconvolution of the RBS spectrum in their individual element components is shown for the samples deposited for 2 and $20 \mathrm{~min}$. A three-layer stack model was applied for fitting of the measured spectra: (i) the deposited aluminium layer, (ii) an oxygen contribution at the $\mathrm{Al} / \mathrm{Si}$ interface, and (iii) the silicon substrate. Despite the similar atomic number $(\mathrm{Z})$ of aluminium and silicon, the deposited $\mathrm{Al}$ film profile can be clearly discriminated from the Si substrate one. In the spectrum of the sample deposited for $2 \mathrm{~min}$, the Si edge appears at a slightly higher backscattering energy than the $\mathrm{Al}$ edge because of the larger kinematic factor. 
With increasing $\mathrm{Al}$ thickness or depth, the He ions hitting Si have increasingly lower energy. Thus, while the backscattering energy of the high-energy $\mathrm{Al}$ edge remains the same for all thicknesses, the $\mathrm{Si}$ signal is shifted towards lower energies. A pure aluminium thin film was sufficient to simulate the spectrum of the deposited films. This is typical for thin films deposited by FCVA processes. Only for the longest deposition time of $20 \mathrm{~min}$, a residual content of 4 at. \% oxygen was found within the $\mathrm{Al}$ layer (see Table 4). From the calculated RBS areal density (see Table 4) and the measured thickness of the layers (see Table 3), a density of $2.2 \mathrm{~g} \mathrm{~cm}^{-3}$ was obtained for the aluminium deposited films. Pure aluminium films exhibit a density of $2.7 \mathrm{~g} \mathrm{~cm}^{-3}$ [21], thus the FCVA deposited films have a porosity of around $30 \%$. The oxygen contribution shown in the RBS spectra is located at the $\mathrm{Al} / \mathrm{Si}$ interface. This can be clearly assessed as the corresponding narrow peak is shifting towards lower energy channels (higher depths) as the thickness of the aluminium films grows with deposition time. This interfacial oxide layer, related to the native oxide of the silicon wafer, was found to have an areal density of $200 \pm 10 \times 10^{15} \mathrm{at} \mathrm{cm}^{2}$ that would correspond to a thickness of $30 \pm 2 \mathrm{~nm}$, assuming a layer density of $\mathrm{SiO}_{2}\left(2.2 \mathrm{~g} \mathrm{~cm}^{-3}\right)$ [22].

Table 3. Thickness, roughness, and reflectance (total and specular) data measured for samples deposited at $P_{w}=0.1 \mathrm{~Pa}$ on glass substrates at different times. The specular reflectance is an absolute data obtained from universal reflectance accessory (URA) measurements. The uncertainty in the reflectance measurements was estimated to be of $\pm 1 \%$.

\begin{tabular}{ccccc}
\hline $\begin{array}{c}\text { Deposition Time } \\
\text { (min) }\end{array}$ & $\begin{array}{c}\text { Thickness } \\
(\mathbf{n m})\end{array}$ & $\begin{array}{c}\text { Roughness, } \boldsymbol{R} \boldsymbol{a} \\
\mathbf{( n m )}\end{array}$ & $\begin{array}{c}\text { Total Reflectance } \\
\mathbf{( \% )}\end{array}$ & $\begin{array}{c}\text { Specular Reflectance } \\
\mathbf{( \% )}\end{array}$ \\
\hline 1 & $23 \pm 1$ & $1.5 \pm 0.1$ & 45 & 42 \\
2 & $55 \pm 1$ & $2.1 \pm 0.1$ & 88 & 88 \\
5 & $125 \pm 4$ & $2.9 \pm 0.1$ & 87 & 83 \\
10 & $245 \pm 2$ & $8.6 \pm 0.1$ & 82 & 53 \\
20 & $548 \pm 5$ & $36 \pm 1$ & 78 & 9 \\
\hline
\end{tabular}

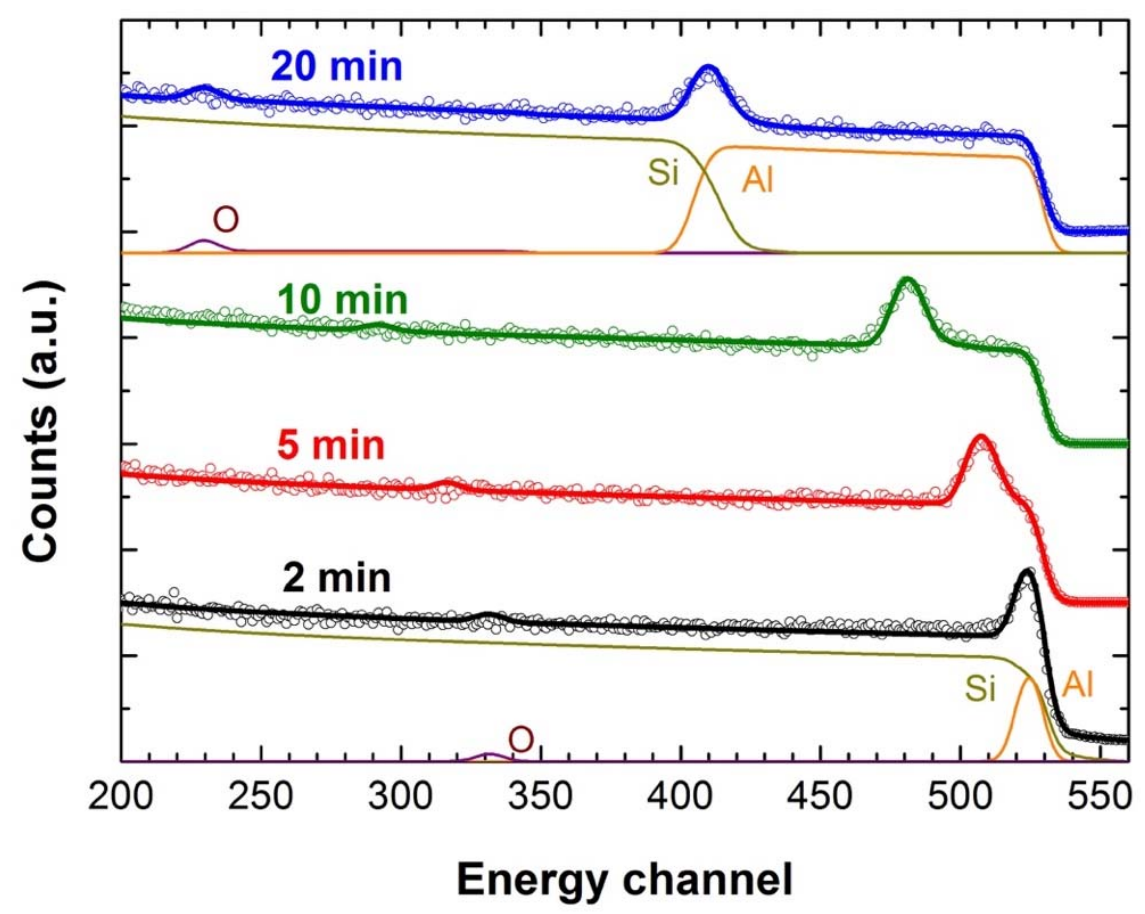

Figure 3. RBS experimental data (open circles) and fitting (continuous lines) for aluminium thin films deposited at $0.1 \mathrm{~Pa}$ at different deposition times on silicon substrates. The elemental decomposition of the spectrum is plotted for the samples deposited for 2 and $20 \mathrm{~min}$. Spectra have been shifted vertically for clarity purposes. 
Table 4. Elemental composition and areal density obtained from Rutherford backscattering spectrometry (RBS) for samples deposited at $P_{w}=0.1 \mathrm{~Pa}$ on silicon substrates at different times. The uncertainty in the chemical composition was estimated to be of $\pm 1 \%$.

\begin{tabular}{cccc}
\hline Time (min) & Al (at $\%)$ & O (at $\%)$ & Areal Density $\left(\times \mathbf{1 0}^{\mathbf{1 5}} \mathbf{a t ~}_{\mathbf{~ c m}}^{\mathbf{- 2}}\right)$ \\
\hline 2 & 100 & 0 & 210 \\
5 & 100 & 0 & 587 \\
10 & 100 & 0 & 1150 \\
20 & 96 & 4 & 2670 \\
\hline
\end{tabular}

Cross-sectional and top view SEM images (Figure 4) reveal an increasing surface roughness and the apparent transition from a two-dimensional (Frank-van der Merwe mode) to a three-dimensional thin film growth mode (Volmer-Weber mode) [23]. While after 2 min deposition, the films have a closed microstructure, an open microstructure with big islands and deep voids approaching the substrate has evolved.
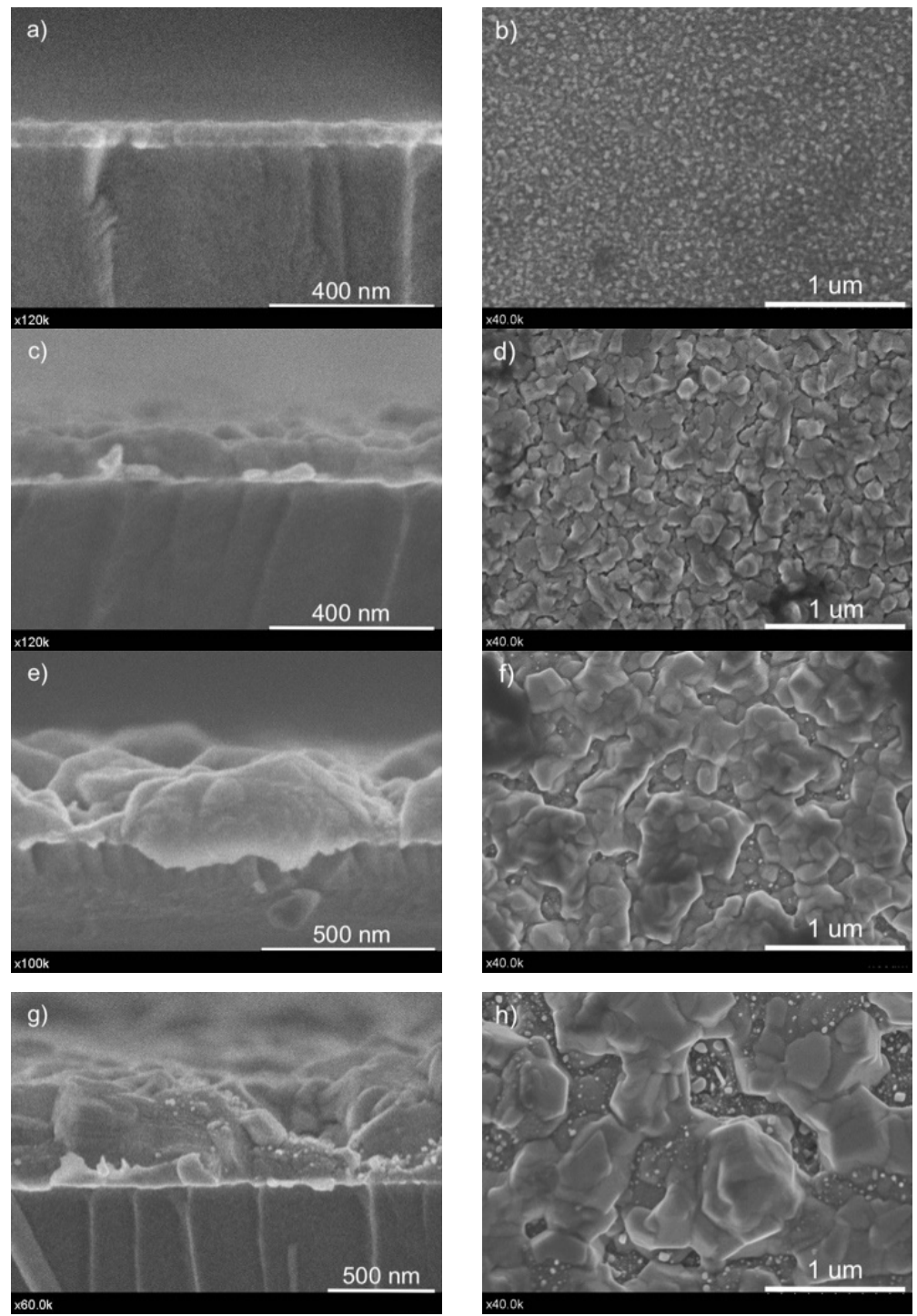

Figure 4. Cross-sectional (a,c,e,g) and top view (b,d,f,h) scanning electron microscopy (SEM) images of samples prepared at $P_{w}=0.1 \mathrm{~Pa}$ on Si substrate. Deposition times from left to right: (a) and (b) $2 \mathrm{~min}$, (c) and (d) $5 \mathrm{~min}$, (e) and (f) $10 \mathrm{~min}$, and (g) and (h) $20 \mathrm{~min}$. 
SEM analysis (Figure 4) was complemented with AFM measurements. AFM images of $10 \times 10 \mu \mathrm{m}$ are shown in Figure 5 for samples deposited at different times $(t=2-20 \mathrm{~min})$. The increase of surface roughness with deposition time is also evident in this scale. For short deposition times, the surface presents a very smooth and featureless morphology that turns into a granular morphology with a mean grain size growing from $170 \mathrm{~nm}$ at $5 \mathrm{~min}$ deposition time to $425 \mathrm{~nm}$ at 20 min deposition time.
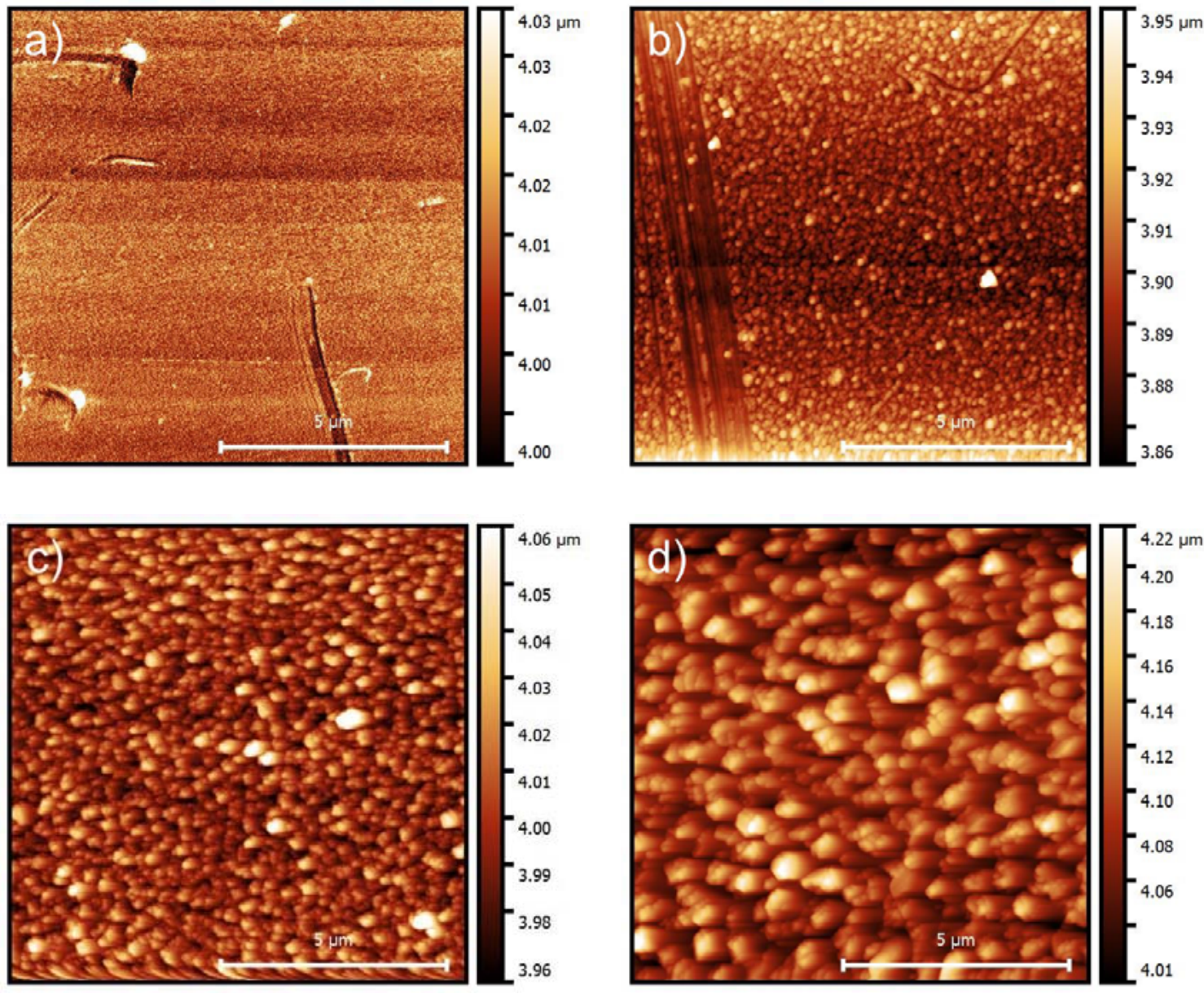

Figure 5. Atomic force microscopy (AFM) images of samples deposited at $0.1 \mathrm{~Pa}$ and at different deposition times. From top left to bottom right: (a) $2 \mathrm{~min}$, (b) $5 \mathrm{~min}$, (c) $10 \mathrm{~min}$, and (d) $20 \mathrm{~min}$.

In addition, the dynamics of the surface growth were characterized by means of a dynamic scaling theory (DST) approach [24,25]. In short, within the framework of DST, the roughness $\sigma$ is defined as the mean square deviation of the local height, $h$, with respect to the mean height $<h(t)>$ :

$$
\sigma(t)=\left\langle[h(\boldsymbol{r}, t)-\langle h(t)\rangle]^{2}\right\rangle^{0.5}
$$

where $h(r, t)$ is the growing surface with $r$ a vector in the base plane, $t$ the deposition time, and $\langle\ldots>$ represents the average over all $r$ in a given area. Under the assumptions of standard Family-Vicsek dynamic scaling, there are specific scaling relationships of the temporal and spatial dependences of $\sigma$. In particular, the evolution of the surface roughness with the deposition time: $\sigma \approx t^{\beta}$. The growth exponent $(\beta)$ can be determined by following the change of $\sigma$ with time as can be observed in Figure 6. From the log-log plot of the surface roughness at different deposition times, two different growth regimes can be observed. For deposition times below $5 \mathrm{~min}$, there is a monotonous but slow increase of roughness with time $\sigma \approx t^{0.4}$. From this stage on, there is abrupt change in the growth dynamics and the surface roughness increases at a much faster pace $\sigma \approx t^{2.0}$. 


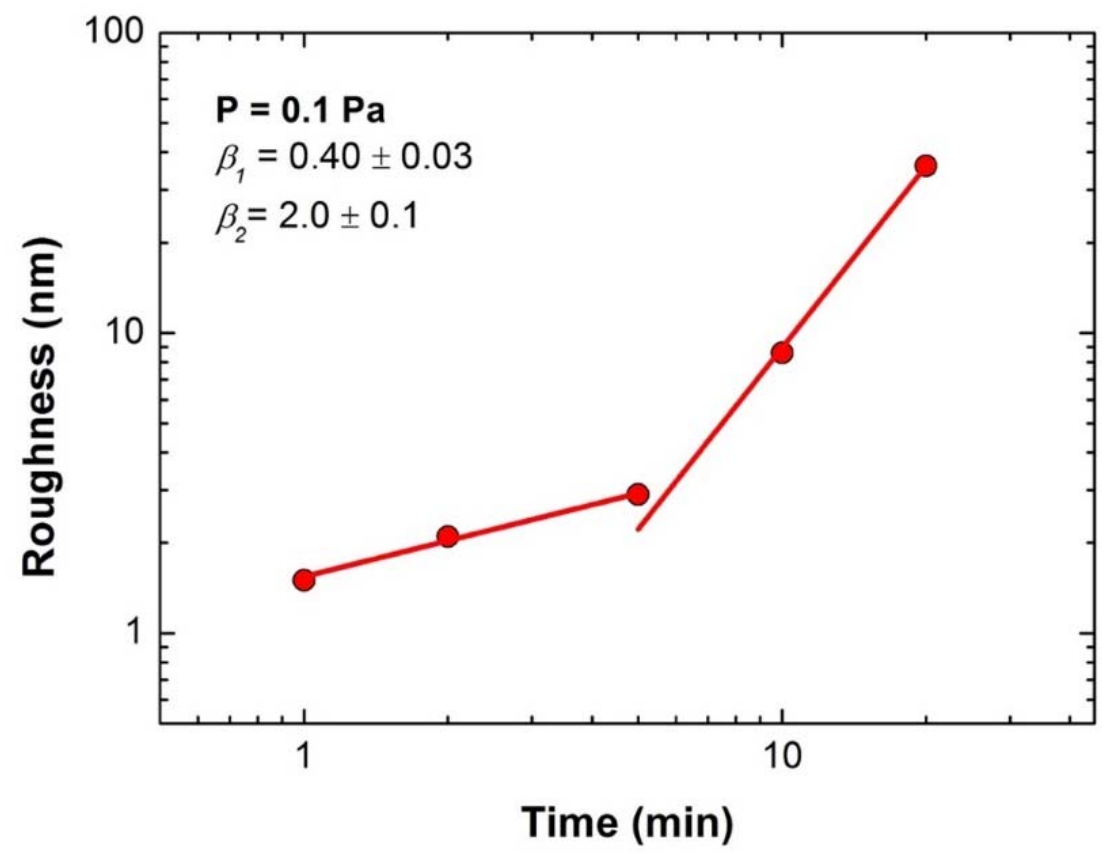

Figure 6. Temporal evolution of surface roughness $(\sigma)$ during filtered cathodic vacuum arc (FCVA) aluminium deposition. Two growth exponents $\left(\beta_{1}\right.$ and $\left.\beta_{2}\right)$ were detected for times $t<5$ and $t>5 \mathrm{~min}$, respectively. The errors in roughness are smaller than the data point size.

The observed changes in the sample morphologies and, in particular, the two different growth mechanisms, are responsible for the optical properties of the deposited aluminium thin films. In Figure 2, it is shown that samples prepared under short deposition times ( 2 and $5 \mathrm{~min}$ ) showed a mirror-like appearance that turned into an opaque whitish colour for longer deposition times (10 and $20 \mathrm{~min}$ ). As inferred from RBS results, this change in appearance cannot be attributed to a compositional change in the films (i.e., formation of a white alumina oxide layer due to the surface oxidation of aluminium). Contrarily, this change is related to a variation in the contribution of the specular component of the sample reflectance. In Figure 7, the total and specular reflectance are shown for the case of aluminium film deposited at $0.1 \mathrm{~Pa}$ for (top) $2 \mathrm{~min}$ and (bottom) $20 \mathrm{~min}$. In the first case, the reflectance is almost purely specular ( $99.8 \%$ of the total reflectance), while the contribution of the specular reflectance to the total reflectance decreases enormously (down to $12 \%$ ) for longer deposition times.

This behaviour correlates well with the observed changes in the surface roughness and grain size and the different growth regimes derived from DST analysis. In Table 3, the data of total and specular reflectance of the deposited samples are summarized and in Figure 8, the total and specular reflectance together with the roughness of the samples are plotted versus the layer thickness. The thinnest layer of $22 \mathrm{~nm}$ ( 1 min deposition) still presents a semi-transparent performance with a total reflectance of around $42 \%$. The total reflectance increases up to $87-88 \%$ with layer thickness for samples thinner than $120 \mathrm{~nm}$ (2 to $5 \mathrm{~min}$ deposition). This corresponds with the first regime of growth of DST that was characterised by a slow increase of the surface roughness (from 1.5 to $3 \mathrm{~nm}$ ) and grain size with thickness. As stated above, the main contribution (99-95\%) to this reflectance comes from the specular component and is in this range, at $2 \mathrm{~min}$ specifically, where best results for specular reflectance were measured. Although there is a small decrease of the total reflectance of thicker samples $(78 \%$ for a $544 \mathrm{~nm}$ layer), probably related to light absorption, the most remarkable observation is the abrupt change of the specular reflectance of those samples. It decreases from $83 \%$ for a $122 \mathrm{~nm}$ layer down to $53 \%$ and $9 \%$ for 244 and $559 \mathrm{~nm}$ films, respectively. This behaviour is aligned with the increase up to an order of magnitude of the surface roughness of these samples (from 3 to 36 $\mathrm{nm})$ and the appearance of large surface grains $(>400 \mathrm{~nm})$. It seems plausible that this increase of 
roughness and grain size produces the scattering of light on the thin film surface and, therefore, the diffuse component of the reflectance becomes predominant in these samples. It is worth noting that the thickest aluminium sample presents a relatively high total reflectance (around $80 \%$ ) with a $90 \%$ diffuse component. This opens the possibility of using such films a diffuse metal standard as an alternative to typical commercial reference materials made, such as $\mathrm{BaSO}_{4}$ or Spectralon used by commercial spectrophotometer manufacturers. It is important to remark that one of the great advantages of such a standard is that it could be complemented with a specular standard made of the same material (aluminium).
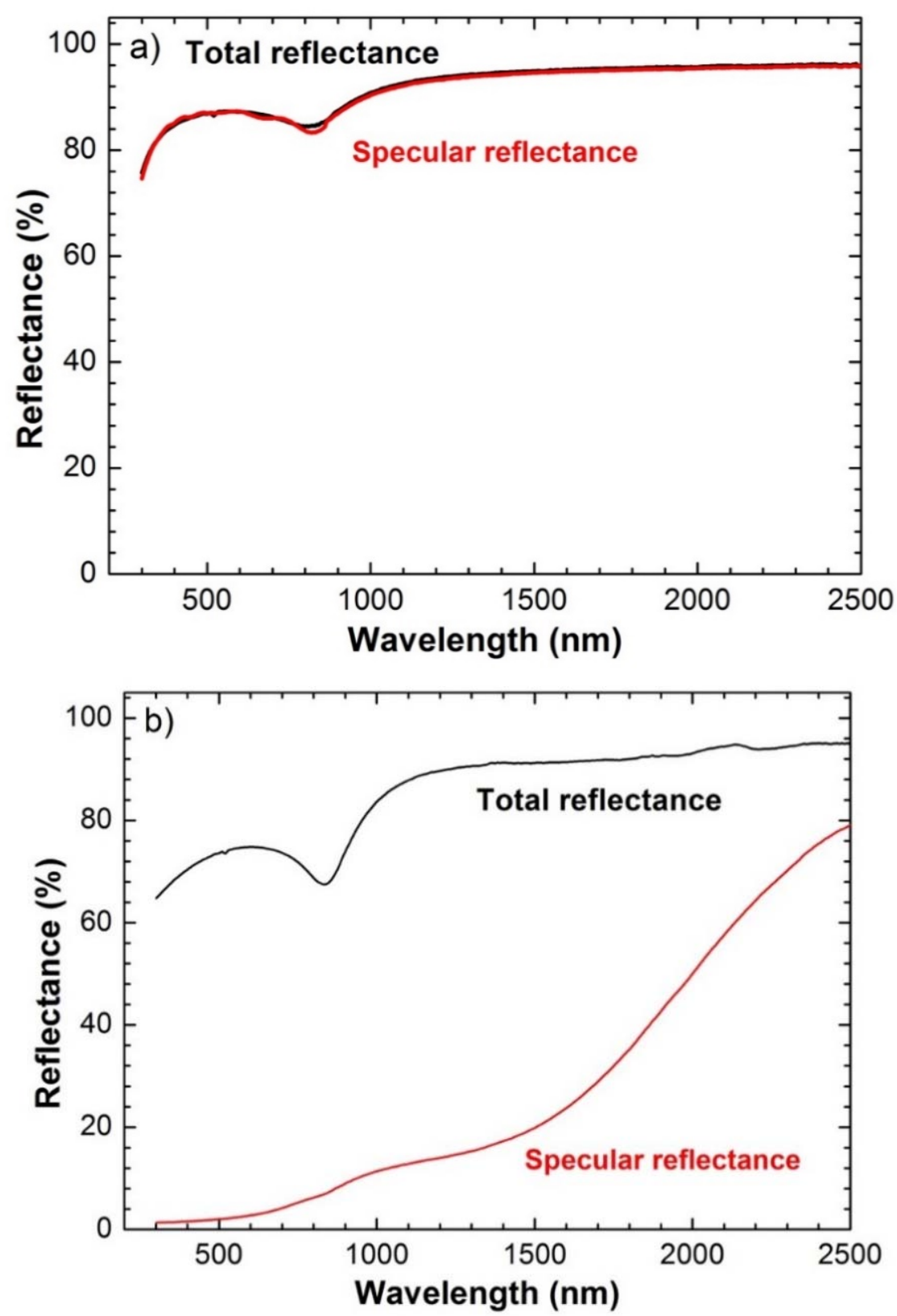

Figure 7. Total and specular reflectance of aluminium thin films deposited for (a) 2 min and (b) $20 \mathrm{~min}$ at $0.1 \mathrm{~Pa}$ on glass substrates. 


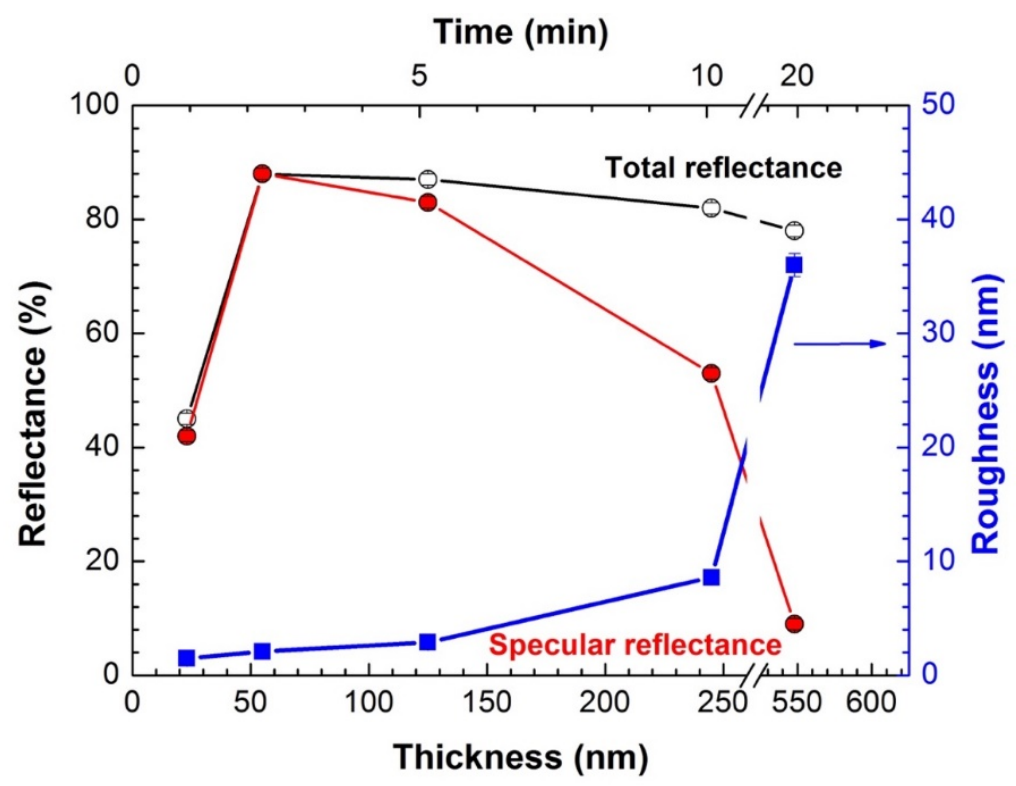

Figure 8. On the left axis, in red and black, total and specular reflectance changes, respectively, depending on the thickness of the film. On the right axis, in blue, roughness changes with thickness.

\section{Conclusions}

The aim of this paper was to optimise deposition parameters of aluminium thin films to obtain maximum specular reflectance using filtered cathodic vacuum arc. Deposition conditions of aluminium thin films were shown to have a massive impact on thin film properties and microstructure. The transparency of the samples increases with the working pressure (for a fixed deposition time) due to a decrease of the deposition rate of the samples. This is easily apparent already from the comparison of samples with similar thickness, but grown at different pressures and rates, namely the samples deposited in $2 \mathrm{~min}$ at $0.1 \mathrm{~Pa}$ and in $20 \mathrm{~min}$ at $1 \mathrm{~Pa}$, respectively (Figure 2). The resulting thicknesses of $56 \mathrm{~nm}$ and $40 \mathrm{~nm}$ are not much different. However, the first sample was well-reflecting, and the latter one was transparent. Working at a fixed pressure of $0.1 \mathrm{~Pa}$, samples showed a transition from a mirror-like appearance to opaque whitish colour for longer deposition times. RBS spectra showed that this change in reflectance could not be attributed to the surface oxidation of the films, but to a dramatic increase ( 20 times) of the surface roughness with deposition time. This increase was confirmed by SEM, profilometry, and AFM measurements. Consequently, the specular contribution to the total reflectance of the films dropped from $99.8 \%$ in the case of films deposited for 2 min, down to $12 \%$ in the case of films deposited for $20 \mathrm{~min}$. These results were correlated with the presence of two different growth regimes as derived from dynamic scaling analysis. In the first regime (deposition times $\leq 5 \mathrm{~min}$ ), the roughness slowly increases with time $\left(\sigma \approx t^{0.4}\right)$ leading to the deposition of highly specular reflecting aluminium thin films. For longer deposition times, the surface roughness increases rapidly $\left(\sigma \approx t^{2.0}\right)$ and highly diffusive reflecting aluminium films are grown.

The $88 \%$ maximum specular reflectance obtained with optimised aluminium thin films in this study is still far from the $95 \%$ values that solar collectors mirror uses today. However, it paves the way for further optimisation using the thin films developed here. This optimization would include exploring other experimental parameters (in particular, the growth temperature) and the deposition of dielectric multilayers on top of the metal film [26].

These results could be also applied to create diffuse aluminium standard as an alternative to typical commercial materials as such $\mathrm{BaSO}_{4}$ or Spectralon. This can greatly contribute to the accuracy in the reflectance measurement and performance comparison of materials whose specular and diffuse components of the total reflectance are very much dependent on the deposition conditions. 
Author Contributions: Conceptualisation: G.R.-L., R.E.-G., and M.K.; Formal Analysis: R.E.G. and G.R.-L.; Investigation: G.R.-L., I.H., E.S., and E.G.R.; Project administration: Escobar-Galindo R.E.-G.; Resources: G.R.-L.; Supervision: R.E.-G. and M.K.; Validation: G.R.-L. and R.E.-G.; Visualisation: G.R.-L. and R.E.-G.; Writing-Original draft: G.R.-L. and R.E.-G.; Writing—review \& editing G.R.-L., E.G.R., I.H., E.S., M.K., and R.E.G.

Funding: This project was partially funded by the EU H2020 RISE project "Framework of Innovation for Engineering of New Durable Solar Surfaces (FRIENDS2, GA-645725)" and by Junta de Castilla y León through the support of the European Regional Development Funds (No. SA017P17).

Acknowledgments: Support by the Ion Beam Centre (IBC, Helmholtz-Zentrum Dresden-Rossendorf) is gratefully acknowledged. The authors would like to thank $\mathrm{M}^{\mathrm{a}} \mathrm{C}$. Jiménez de Haro (Instituto Ciencia y Tecnología de Materiales de Sevilla) for the SEM service and Bertrand Lacroix (University of Cadiz, IMEYMAT) for the analysis of AFM images to obtain the different mean grain sizes. Any opinions, findings, and conclusions or recommendations expressed in this material are those of the authors and do not necessarily reflect those of the host institutions or funders.

Conflicts of Interest: The authors declare no conflict of interest.

\section{References}

1. California Energy Commission. Ivanpah Solar Electric Generating System. Available online: http:/ / www. energy.ca.gov / sitingcases/ivanpah/index.html (accessed on 13 September 2018).

2. 67th Edition of BP's Statistical Review of World Energy. Available online: https://www.bp.com/content/ $\mathrm{dam} / \mathrm{bp} / \mathrm{en} /$ corporate/pdf/energy-economics/statistical-review/bp-stats-review-2018-full-report.pdf (accessed on 13 September 2018).

3. Zhang, H.L.; Baeyens, J.; Degreve, J.; Caceres, G. Concentrated solar power plants: Review and design methodology. Renew. Sustain. Energy Rev. 2013, 22, 466-481. [CrossRef]

4. Selvakumar, N.; Barshilia, H.C. Review of physical vapor deposited (PVD) spectrally selective coatings for mid- and high-temperature solar thermal applications. Sol. Energy Mater. Sol. Cells 2012, 98, 1-23. [CrossRef]

5. Fenker, M.; Balzer, M.; Kappl, H. Corrosion protection with hard coatings on steel: Past approaches and current research efforts. Surf. Coat. Technol. 2014, 257, 182-205. [CrossRef]

6. Heller, P. The Performance of Concentrated Solar Power (CSP) Systems: Analysis, Measurement and Assessment; Woodhead Publishing Series in Energy; Woodhead Publishing: Cambridge, MA, USA, 2017.

7. Good, P.; Cooper, T.; Querci, M.; Wiik, N.; Ambrosetti, G.; Steinfeld, A. Spectral reflectance, transmittance, and angular scattering of materials for solar concentrators. Sol. Energy Mater. Sol. Cells 2016, 144, 509-522. [CrossRef]

8. Sansom, C.; Comley, P.; Bhattacharyya, D.; Macerol, N. A comparison of polymer film and glass collectors for concentrating solar power. Energy Procedia 2014, 49, 209-219. [CrossRef]

9. State of the Art in Heliostats and Definition of Specifications. Available online: https://www.stage-ste.eu/ deliverables/STAGE_STE_Deliverable_12_1.pdf (accessed on 13 September 2018).

10. Brogren, M.; Helgesson, A.; Karlsson, B.; Nilsson, J.; Roos, A. Optical properties, durability, and system aspects of a new aluminium-polymer-laminated steel reflector for solar concentrators. Sol. Energy Mater. Sol. Cells 2004, 82, 387-412. [CrossRef]

11. Chiba, K.; Suzuki, K. Effects of heterogeneous metal atoms on the stability of a silver layer of a heat mirror coating. Sol. Energy Mater. Sol. Cells 1992, 25, 113-123. [CrossRef]

12. Hernandez, T.; Moroño, A.; Hodgson, E.R. Radiation enhanced degradation of aluminium mirrors for remote handling and diagnostics applications: Effect of humidity. Sol. Energy Mater. Sol. Cells 2003, 69, 177-182. [CrossRef]

13. Mishra, S.K.; Kumar, V.; Tiwari, S.K.; Mishra, T.; Angula, G.; Adhikari, S. Development and degradation behavior of protective multilayer coatings for aluminum reflectors for solar thermal applications. Thin Solid Films 2016, 619, 202-207. [CrossRef]

14. Garcia-Segura, A.; Fernandez-Garcia, A.; Ariza, M.J.; Sutter, F.; Valenzuela, L. Durability studies of solar reflectors: A review. Renew. Sustain. Energy Rev. 2016, 62, 453-467. [CrossRef]

15. Heras, I.; Krause, M.; Abrasonis, G.; Pardo, A.; Endrino, J.L.; Guillen, E.; Escobar-Galindo, R. Advanced characterization and optical simulation for the design of solar selective coatings based on carbon: Transition metal carbide nanocomposites. Sol. Energy Mater. Sol. Cells 2016, 157, 580-590. [CrossRef] 
16. International Organization for Standardization. Geometrical Product Specifications (GPS)—Surface Texture: Profile Method-Terms, Definitions and Surface Texture Parameters; ISO4287-1997; International Organization for Standardization: Geneva, Switzerland, 1997.

17. International Organization for Standardization. Glass in Building_Determination of Light Transmittance, Solar Direct Transmittance, Total Solar Energy Transmittance, Ultraviolet Transmittance and Related Glazing Factors; ISO9590:2003; International Organization for Standardization: Geneva, Switzerland, 2003.

18. SIMNRA. Computer Simulation of RBS, ERDA, NRA and MEIS. Available online: http:/ /home.mpcdf.mpg. de/ mam/ (accessed on 13 September 2018).

19. Mahan, J.E. Materials Science Special Topics. In Physical Vapor Deposition of Thin Films; Mahan, J.E., Ed.; Wiley-VCH: Weinheim, Germany, 2000; p. 336.

20. Albella, J.M. Láminas Delgadas y Recubrimientos, Preparación, Propiedades y Aplicaciones; Editorial CSIC-CSIC Press: Madrid, Spain, 2003.

21. Hartman, T.E. Density of thin evaporated aluminum films. J. Vac. Sci. Technol. 1965, 2, 239-242. [CrossRef]

22. Nastasi, M.; Mayer, J.W.; Ael, Y.W. Ion Beam Analysis: Fundamentals and Applications; CRC Press: Boca Raton, FL, USA, 2014.

23. Michely, T.; Krug, J. Islands Mounds and Atoms; Springer Science \& Business Media: New York, NY, USA, 2004.

24. Barabási, A.L.; Syanley, H.E. Fractal Concepts in Surface Growth; Cambridge University Press: Cambridge, MA, USA, 1995.

25. Cuerno, R.; Vázquez, L. Advances in Condensed Matter and Statistical Physics; Nova Publishers: New York, NY, USA, 2004.

26. Jimenez-Solano, A.; Anaya, M.; Calvo, M.E.; Alcon-Camas, M.; Alcañiz, C.; Guillen, E.; Martinez, N.; Gallas, M.; Preussner, T.; Escobar-Galindo, R.; et al. Aperiodic metal-dielectric multilayers as highly efficient sunlight reflectors. Adv. Opt. Mater. 2017, 5, 1600833. [CrossRef]

(C) 2018 by the authors. Licensee MDPI, Basel, Switzerland. This article is an open access article distributed under the terms and conditions of the Creative Commons Attribution (CC BY) license (http:/ / creativecommons.org/licenses/by/4.0/). 